\title{
Development and Evaluation of Mouth Dissolving Tablets using Natural Super Disintegrants
}

\author{
Venkatalakshmi Ranganathan*1, Jason Yoong ${ }^{2}$ \\ ${ }^{1}$ School of Pharmacy, MAHSA University, Jalan SP 2/7, Bandar Saujana Putra, Jenjarom, Selangor, MALAYSIA. \\ ${ }^{2}$ School of Pharmacy, International Medical University, Bukit Jalil, Kuala Lumpur, MALAYSIA.
}

\begin{abstract}
Objective: To formulate a mouth dissolving tablets of dexamethasone for the use of paediatrics, geriatric patients and also dysphagic patients. Methodology: Tablets were formulated by using different types of natural Super disintegrants in different concentration such as Guar gum and Xanthan gum. A manual $7 \mathrm{~mm}$ single punch tablet compression machine was used to compress the tablet. Powder mixture of $150 \mathrm{mg}$ was weighed accurately and added into the die cavity. The prepared dexamethasone MDT tablets were evaluated for its physico-chemical parameters such as thickness, hardness, weight variation, friability, disintegration time, wetting time, in-vitro dispersion time, water absorption ratio and also in-vitro drug release. Results: The FTIR and DSC studies conferred that there is no interaction between dexamethasone and Super disintegrants. The dissolution profile of dexamethasone MDT compared with conventional dexamethasone tablet shows improved in \% drug release and faster \% drug release. An increase in the concentration of Super disintegrants showed
\end{abstract}

faster $\%$ of drug release and similar \% of cumulative drug release. Conclusion: Dexamethasone MDT using Guar Gum and Xanthan Gum could be considered as good formulation and delivery system to increase the patient's compliance as the \% drug release and disintegration time are much better than conventional Dexamethasone tablet.

Key words: Mouth Dissolving Tablets, dexamethasone, Super disintegrants, Rapid disintegration, Dysphagia.

Correspondence :

Dr. Venkatalakshmi Ranganathan, B.Pharm., M.Pharm., Ph.D.

Department of Dosage Form Design, Faculty of Pharmacy, MAHSA University, Bandar Saujana Putra, Jenjarom, Selangor, MALAYSIA.

Email: rvenkatmpharm@gmail.com, lakshmi@mahsa.edu.my

DOI: 10.5530/jyp.2017.9.66

\section{INTRODUCTION}

There are quite a number of patients find it hard to swallow tablets as there is physiological changes associated with people especially elderly and pediatrics. Therefore, in order to solve this problem, this project is conducted so that the patients compliance can be improved, a new dosage form convenient for use by geriatric and pediatric dysphagic patients are formulated; reduce the cost of medication for those patients who cannot afford, and also to produce improved products which are available in the market. $^{1-5}$

Dexamethasone, an antiemetic drug which is model drug mostly used as an antiemetic for post-operative and patients undergo chemotherapy. Dexamethasone has a central antiemetic action through activation of glucocorticoid receptors in bilateral nucleus tractus solitarii. The dose that was being chosen are $4 \mathrm{mg}$. The chemical formula of dexamethasone is $\mathrm{C} 22 \mathrm{H} 29 \mathrm{FO} 5$.

\section{MATERIALS AND METHODS}

Dexamethasone, Croscarmellose sodium and guar gum were purchased from Sigma-Aldrich MALAYSIA. Other excipients such as mannitol, sucralose, starch, vanillin and magnesium stearate used and all other reagents used were of analytical grade.

\section{Determination of $\lambda_{\max }$ of Dexamethasone and preparation of calibration curve}

Dexamethasone $10 \mathrm{mg}$ was weighed accurately and was completely dissolved in methanol in volumetric flask. The solution was then topped up to $100 \mathrm{ml}$ with methanol to give concentration of $0.1 \mathrm{mg} / \mathrm{ml}$. Then, $1 \mathrm{ml}$ was pipetted out from the flask and again topped up to $100 \mathrm{ml}$ with methanol to give concentration of $1 \mu \mathrm{g} / \mathrm{ml}$. Aliquots of $1 \mathrm{ml}, 2 \mathrm{ml}, 3 \mathrm{ml}$, $4 \mathrm{ml}, 5 \mathrm{ml}$ and $6 \mathrm{ml}$ were pipetted out in $10 \mathrm{ml}$ volumetric flask. ${ }^{10,11}$ The volume was diluted with methanol to give concentration of $0.1,0.2$, $0.3,0.4,0.5$ and $0.6 \mu \mathrm{g} / \mathrm{ml}$ dexamethasone respectively. A best UV wavelength $(\lambda \max )$ was selected by using spectroscopic scanning run (200-400 nm) with the reference solution and was found to be $239 \mathrm{~nm}$.

\section{Formulation of Mouth Dissolving Tablets}

Dexamethasone, natural Super disintegrants, mannitol, magnesium stearate, starch, sucralose and vanillin are being mixed uniformly using geometric trituration and also being weighed accurately prior to compression. Then, a manual tablet compression machine with manual $7 \mathrm{~mm}$ single punch was used to compress powder into tablet form. Powder mixture of $150 \mathrm{mg}$ is weighed accurately and added into the die cavity. Lastly, tablets of $150 \mathrm{mg}$ each was produced after compression by the machine. ${ }^{7-9}$ The composition of dexamethasone mdt is shown in Table 1.

\section{Compatibility studies ${ }^{6-10}$ \\ Fourier Transform Infrared Spectroscopy}

FTIR spectra of the pure drug, excipients, and prepared solid dispersions were obtained on a FTIR. Samples were prepared in $\mathrm{KBr}$ disks (2 mg sample in $200 \mathrm{mg} \mathrm{KBr}$ ). The scanning range was $400-4000 \mathrm{~cm}-1$, and the resolution was $1 \mathrm{~cm}-1$.

\section{Differential Scanning Calorimetry}

The DSC thermo gram of pure drug, Super disintegrants, and solid dispersions were recorded on a DSC. The samples were weighed and 


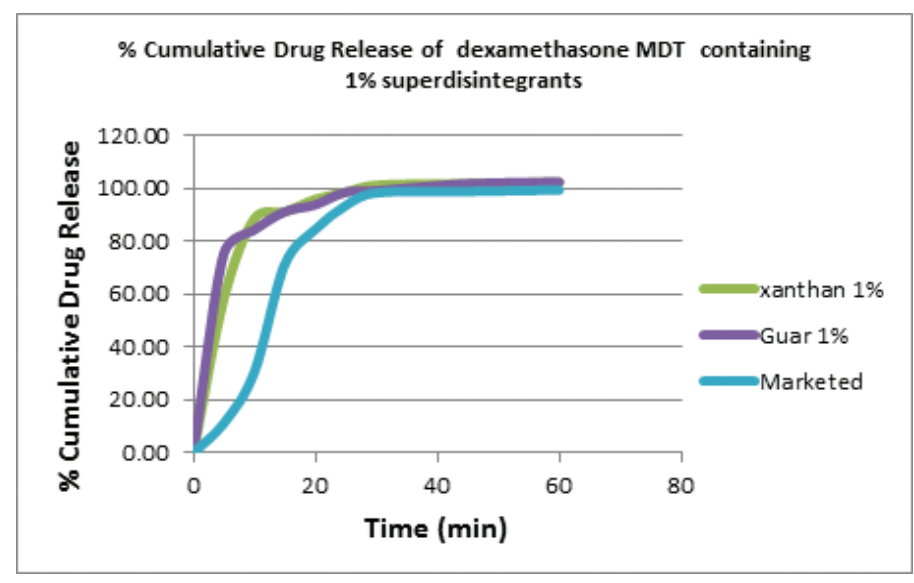

Figure 1: \% Cumulative Drug Release of dexamathasone mdt containing 1\% xanthan gum, guar gum and marked product

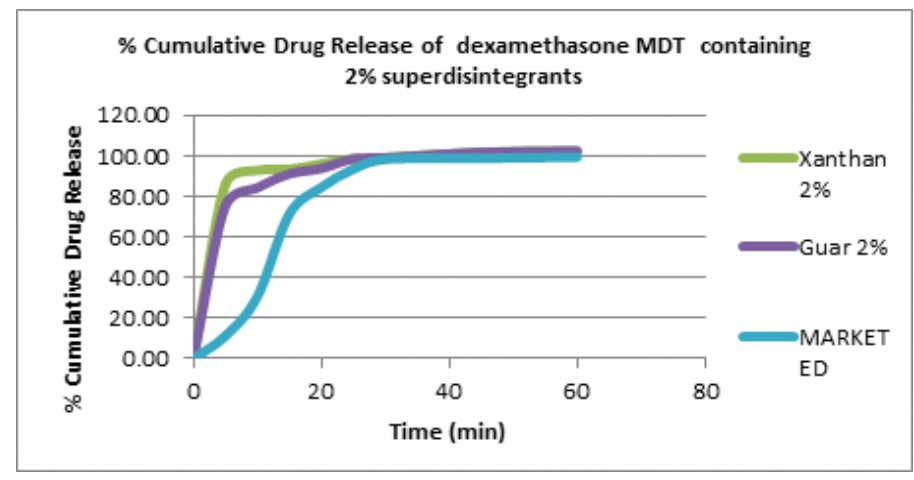

Figure 2: \% Cumulative Drug Release of dexamathasone mdt containing 2\% xanthan gum, guar gum and marked product

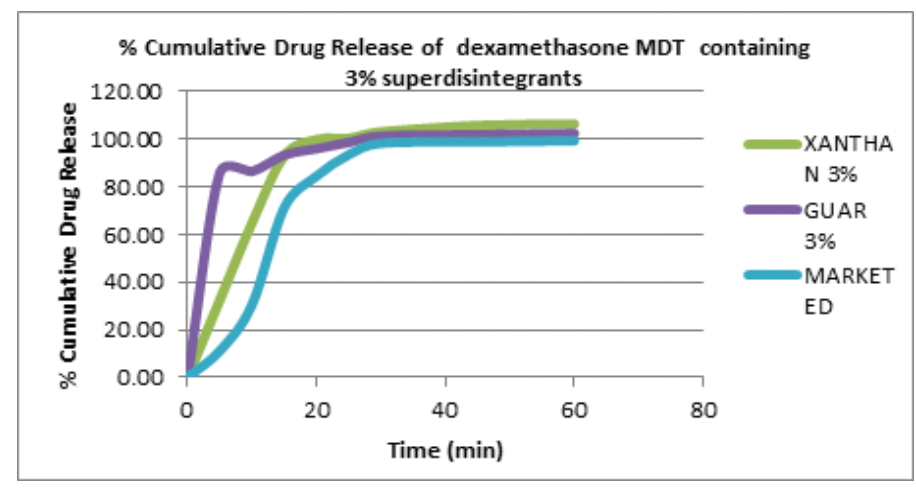

Figure 3: \% Cumulative Drug Release of dexamathasone mdt containing 3\% xanthan gum, guar gum and marked product

heated in hermetically sealed aluminum pans over a temperature range of $50-300^{\circ} \mathrm{C}$

\section{Physicochemical Evaluation of Mouth Dissolving Tablets ${ }^{7-11}$ Weight Variation}

Ten tablets were selected randomly from each batch and weighed individually to check for weight variation. The following percentage deviation in weight variation is allowed as per USP.

\section{Thickness}

Vernier calipers was being used to measure the thickness.

\section{Hardness}

Monsanto hardness tester Hardness was used to determine the hardness of tablets.

\section{Friability}

Ten tablets were accurately weighed and placed in the friabilator and undergo 100 revolutions. Percentage friability was calculated using the following formula.

$\mathrm{F}=(1-\mathrm{W} 0 / \mathrm{W}) \times 100$, Where, $\mathrm{W} 0$ is the weight of the tablet before the test and $\mathrm{W}$ is the weight of the tablet after the test.

\section{Disintegration Time}

Three tablets were being taken and being placed into each tube of USP disintegration apparatus (distilled water $900 \mathrm{ml}$ at $37^{\circ} \mathrm{C}$ ) as the disintegrating medium. The experiment was being done in room temperature.

\section{Wetting Time}

Three tablets were being taken for this test. A petri dish was filled up with $10 \mathrm{ml}$ of distilled water. Then, a tissue paper folded twice was placed into the petri dish. The time to for the tablet to wet completely was observed after a tablet was placed on the paper.

\section{In-vitro Dispersion Time}

Three tablets were taken for this test. $6 \mathrm{ml}$ phosphate buffer solution, $\mathrm{pH}$ $6.8 \pm 0.5^{\circ} \mathrm{C}$ was prepared before each tablet was being placed. Then, the time for complete dispersion of a tablet was observed.

\section{Water Absorption Ratio}

A petri dish was filled up with $10 \mathrm{ml}$ of distilled water. Then, a tissue paper folded twice was placed into the petri dish. A tablet was placed on top of the paper and pre-weight of tablets was determined. Then, the tablet which was wet are weighed. Water absorption ratio $\mathrm{R}$, was determined using equation.

$$
R=\{(W a-W b) / W b\} \times 100
$$

Where, $\mathrm{Wa}=$ weight of the tablet before water absorption $\mathrm{Wb}=$ weight of the tablet after water absorption. Three tablets from each formulation were analyzed and standard deviation was determined. The results were shown in table 2.

\section{In-vitro Drug Release ${ }^{11}$}

Three tablets from each formulation were being placed into the Electro lab TDT-08L Dissolution Tester. The medium used were $900 \mathrm{ml}$ of phosphate buffer pH 6.8 for MDT and $500 \mathrm{ml}$ of dilute HCL buffer for conventional marketed Dexamethasone tablets. Temperature was set at $37 \pm 0.5^{\circ} \mathrm{C}$; speed at 50 cycles per minute; sample interval was $5 \mathrm{~min}$, $10 \mathrm{~min}, 15 \mathrm{~min}, 30 \mathrm{~min}, 45 \mathrm{~min}$ and 1 hour; sample volume was $5 \mathrm{ml}$, replacing the aliquots with fresh buffer solution after withdrawing. The drug release and different kinetic models were shown in Table 3 and Figure 1-3.

\section{RESULTS AND DISCUSSION}

There was no interaction between the drug and natural Super disintegrants according to the results obtained from FTIR and DSC and it shows that drug and polymer are compatible each other.

Thickness found was in the range of 2.5-3.0 mm, hardness was between $2-3 \mathrm{~kg} / \mathrm{cm}^{2}$ and it is important for MDT for achieving fast disintegration, weight variation found to be in between $146.7 \mathrm{mg}-129.1 \mathrm{mg}$, friability 
Venkatalakshmi.R et al.,: Development and Evaluation of Mouth Dissolving Tablets using Natural Super Disintegrants

Table 1: Formulation of Dexamethasone Loaded Mouth Dissolving Tablets

\begin{tabular}{ccccccc}
\hline Ingredients $(\mathbf{m g})$ & \multicolumn{7}{c}{ Formulation code } \\
\cline { 2 - 7 } & XG1 & XG2 & XG3 & GG1 & GG2 & GG3 \\
\hline Dexamethasone & 0.75 & 0.75 & 0.75 & 0.75 & 0.75 & 0.75 \\
Mannitol & 128.25 & 126.75 & 125.25 & 128.25 & 126.75 & 125.25 \\
Sucralose & 3.0 & 3.0 & 3.0 & 3.0 & 3.0 & 3.0 \\
Xanthan Gum & 1.5 & 3.0 & 4.5 & - & - & - \\
Guar Gum & - & - & - & 1.5 & 3.0 & 4.5 \\
Starch & 12.5 & 12.5 & 12.5 & 12.5 & 12.5 & 12.5 \\
Magnesium Stearate & 3.0 & 3.0 & 3.0 & 3.0 & 3.0 & 3.0 \\
Vanillin & 1.0 & 1.0 & 1.0 & 1.0 & 1.0 & 1.0 \\
Total weight & 150 & 150 & 150 & 150 & 150 & 150 \\
Vanillin & 1.0 & 1.0 & 1.0 & 1.0 & 1.0 & 1.0 \\
\hline
\end{tabular}

Table 2: Results for Physicochemical Parameters of Dexamethasone MDT

\begin{tabular}{ccccccc}
\hline Parameters & XG 1 & XG 2 & XG 3 & GG 1 & GG 2 & GG 3 \\
\hline Thickness $(\mathrm{mm})$ & 2.85 & 2.73 & 2.59 & 2.67 & 2.72 & 2.72 \\
Hardness 2-3 $\left(\mathrm{kg} / \mathrm{cm}^{2}\right)$ & 2.90 & 2.77 & 2.93 & 2.93 & 2.70 & 2.60 \\
Weight Variation SD $<4.5 \%(\mathrm{mg})$ & $149.1 \pm 1.8$ & $149 \pm 1.3$ & $149 \pm 1.8$ & $147.9 \pm 2.2$ & $146.7 \pm 3.2$ & $148.6 \pm 1.5$ \\
Friability <1\% (\%) & 0.57 & 0.71 & 0.51 & 0.98 & 0.73 & 0.91 \\
Disintegration Time <60 (sec) & 63 & 58.67 & 48.67 & 43.67 & 39.33 & 38.33 \\
Wetting Time (sec) & 160 & 126.33 & 124 & 53.33 & 47 & 45.33 \\
In- vitro Dispersion Time (sec) & 119 & 101.67 & 59.33 & 55.67 & 52.67 & 34.33 \\
Water Absorption Ratio (\%) & 0.55 & 0.58 & 0.67 & 0.71 & 0.83 & 0.94 \\
\hline
\end{tabular}

Table 3: Kinetics of Drug Release of Dexamethasone MDT

\begin{tabular}{|c|c|c|c|c|c|c|c|}
\hline \multirow[t]{2}{*}{ Formulation } & \multicolumn{4}{|c|}{ Correlation Coefficient, $\mathrm{r}^{2}$} & \multirow{2}{*}{$\begin{array}{c}\text { Kinetic } \\
\text { Constant, k }\end{array}$} & \multirow{2}{*}{$\begin{array}{l}\text { Diffusional } \\
\text { Exponent, } n\end{array}$} & \multirow[t]{2}{*}{ Order of Release } \\
\hline & Zero order & First order & Higuchi Model & $\begin{array}{c}\text { Korsemeyer-Peppas } \\
\text { Model }\end{array}$ & & & \\
\hline XG 1 & -0.696 & 0.8248 & 0.579 & 0.749 & 0.494 & 0.202 & Fickian Diffusion \\
\hline $\mathrm{XG} 2$ & -1.289 & 0.7979 & 0.292 & 0.967 & 0.776 & 0.071 & Fickian Diffusion \\
\hline XG 3 & 0.018 & 0.7927 & 0.324 & 0.765 & 0.216 & 0.447 & Fickian Diffusion \\
\hline GG 1 & -0.964 & 0.955 & 0.474 & 0.942 & 0.631 & 0.128 & Fickian Diffusion \\
\hline GG 2 & -1.000 & 0.945 & 0.454 & 0.868 & 0.649 & 0.127 & Fickian Diffusion \\
\hline GG 3 & -1.202 & 0.920 & 0.342 & 0.910 & 0.742 & 0.084 & Fickian Diffusion \\
\hline
\end{tabular}

between $0.57 \%-0.98 \%$, disintegration time between 38.33 -63 seconds and it shows that MDT can disintegrate quickly without access of water, wetting time between 47-160seconds, in-vitro dispersion time between 34.33-119 seconds, water absorption ratio between 0.55 \%-0.9 4\%. All these parameters are shows that dexamethasone is ideal candidate for delivering as mouth dissolving tablet and all physicochemical parameters were in control limits.

The \% drug release for all formulation was between 99.36\%-106.39\%. The release profile showed that formulation containing natural Super disintegrants has higher and faster \% drug release compared to conventional Dexamethasone tablets. The higher the concentration of natural Super disintegrants, the faster the \% drug release and the order of drug release is $1 \%<2 \%<3 \%$.
In-vitro drug release was compared with marketed product of conventional dexamethasone tablet and dexamethasone mdt was showing better and faster drug release than marketed product.

In-vitro drug release was compared with marketed product of conventional dexamethasone tablet and dexamethasone mdt was showing better and faster drug release than marketed product. Kinetics of drug release of dexamethasone MDT shows that diffusional exponent, $\mathrm{n}$ is less than 0.45 and followed fickian diffusion order of drug release.

\section{CONCLUSION}

Tablets and capsules which are currently being considered as the most popular dosage form for oral delivery have some disadvantages to patients undergoing chemotherapy and patients having dysphagia problem. Hence to overcome this problem, current research on Dexamethasone 
MDT using Guar Gum and Xanthan Gum could be considered as good formulation and delivery system to increase the patient's compliance as the $\%$ drug release and disintegration time are much better than conventional Dexamethasone.

\section{ACKNOWLEDGEMENT}

We would like to thank International Medical University for the facilities provided.

\section{CONFLICT OF INTEREST}

The author has no conflict of interest.

\section{ABBREVIATIONS USED}

MDT: mouth dissolving tablet; FTIR: Fourier Transform Infra-Red Spectroscopy; DSC: Differential Scanning Calorimetry; UV: Ultra Violet Spectroscopy; nm: Nanometer; $\mu \mathrm{g}$ : microgram; ml: milliliter; $\mathrm{mm}$ : millimeter; USP: United States Pharmacopeia

\section{REFERENCE}

1. Indhumathi $D$, Rathnam G. Design and optimization of orodissolving tablet of antidepressant drug by Superdisintegrants addition method. Int J Pharm Sci
Rev and Res. 2010;2(2):1-8.

2. Mangal M. Super disintegrants: An Updated Review. Int J Pharm Pharm Sci Res. 2012;2(2):26-35.

3. Kumar GP, Nirmala R. Fundamental aspects of Superdisintegrants: A concise review. J Global Pharm Tech. 2012;4(2):1-12.

4. Sharma V, Arora V, Ray C. Use of Natural Superdisintergrant in Mouth Dissolving Tablet- An Emerging Trend. Int Bull Drug Res. 2010;1(2):46-54.

5. Rao NGR, PatelT, Gandhi S. Development and evaluation of carbamazepine fast dissolving tablets prepared with a complex by direct compression technique. Asian J Pharm Sci. 2009;3(2):97-103. https://doi.org/10.4103/0973-8398.55046.

6. Bhardwaj S, Jain V, Jat RC, Mangal A, Jain S. Formulation and evaluation of fast dissolving tablet of aceclofenac. Intl J Drug Delivery. 2010;2(1):93 https://doi. org/10.5138/ijdd.2010.0975.0215.02017.

7. Mohanachandran PS, Sindhumol PG, Kiran TS. An overview. Int J Pharm Sci Rev and Res. 2011;6(1).

8. Nagar et al. Formulation and Evaluation of Piroxicam Fast Dissolving Tablets using Different Natural Superdisintegrant. J Drug Deliv and Ther. 2014;4(4):55-9.

9. Yellanki SK, Jagtap S, Masareddy R. Dissofilm: A Novel Approach for Delivery of Phenobarbital: Design and Characterization. J Young Pharm. 2011;3(3):181-8.

10. Vasanthan M, Narayanasamy D. Development of Fast Dissolving Tablets of Nisoldipine by Solid Dispersion Technology using Poloxamer 407 and Poloxamer 188. J Young Pharm. 2016;8(4):341-9. https://doi.org/10.5530/jyp.2016.4.9.

11. Nanam PK, Thadkala K, Sailu C, Aukunuru J. Investigation of various practical techniques to enhance dissolution of ezetimibe from oral tablets: A comparative study. J Young Pharm. 2014;6(1):8-14.

Article History: Submission Date : 24-01-2017; Revised Date : 07-03-2017; Acceptance Date : 17-03-2017.

Cite this article: Ranganathan V, Yoong J. Development and Evaluation of Mouth Dissolving Tablets using Natural Super Disintegrants. J Young Pharm. 2017;9(3):332-5. 